\title{
Gestión de la rehabilitación sostenible en Grandes Conjuntos de las periferias urbanas por las administraciones públicas locales
}

\section{Sustainable renovation management of Large Urban Ensembles by local public administrations}

\author{
G. Ruiz Palomeque $^{(*)}$
}

RESUMEN

Parte de las viviendas españolas anteriores al año 1980 ocupan Grandes Conjuntos de las periferias urbanas. Se sitúan en edificios obsoletos y están habitadas por una población vulnerable. Se plantea la «rehabilitación sostenible» de estos Conjuntos, en los aspectos ambientales, económicos y sociales. El contexto actual presenta una serie de barreras, pero también de oportunidades. Algunas ligadas a la nueva financiación de los Fondos de la UE; y otras a la aplicación de la nueva Ley 8/2013 de rehabilitación, renovación y regeneración urbanas. Ésta incluye nuevos tipos de gestión, creando estructuras mixtas público-privadas. Estas estructuras han sido utilizadas en algunas experiencias previas que, a la vista de sus resultados, podrían constituir modelos a seguir para la rehabilitación sostenible de los Grandes Conjuntos Urbanos en España. Se describen los procedimientos seguidos en ellas, dirigidos por las instituciones, y que integran todos los aspectos financieros, de gestión y participación, normativos y técnicos.

Palabras clave: Rehabilitación; gestión; Grandes Conjuntos Urbanos; administraciones públicas.

\section{ABSTRACT}

Part of Spanish dwellings built before 1980 occupy Large Ensembles in urban peripheries. They are located at obsolete buildings and are inhabited by vulnerable population. The "sustainable renovation" of these ensembles is proposed in environmental, economic and social terms. The current context presents a series of barriers, but also of opportunities. Some of the latter linked to the new EU funds; and others to the implementation of the new Law 8/2013 of urban renewal, regeneration and renovation. This law includes new management models, creating public-private mixed structures. These structures have been used in past experiences that, in the light of the results, could constitute models to follow for the sustainable renovation of Large Urban Ensembles in Spain. Description of the procedures followed as ran by the institutions can be found in this paper, integrating all financial, managerial and participation-related, regulatory and technical aspects.

Keywords: Renovation; management; Large Urban Ensembles; public administrations.

(*) Universidad Politécnica de Madrid. Madrid (España).

Persona de contacto/Corresponding author: lgruiz@arquired.es (G. Ruiz Palomeque)

Cómo citar este artículo/Citation: Ruiz Palomeque, G. (2015). Gestión de la rehabilitación sostenible en Grandes Conjuntos de las periferias urbanas por las administraciones públicas locales. Informes de la Construcción, 67(EXTRA-1): mo25, doi: http://dx.doi.org/10.3989/ic.14.047.

Licencia/License: Salvo indicación contraria, todos los contenidos de la edición electrónica de Informes de la Construcción se distribuyen bajo una licencia de uso y distribución Creative Commons Reconocimiento no Comercial 3.o. España (cc-by-nc). 


\section{INTRODUCCIÓN}

En el presente artículo entenderemos por «rehabilitación sostenible» aquella que comprende las intervenciones sobre el parque edificado en la línea de la definición de sostenibilidad entendida en un sentido amplio. En él se incluyen, tanto los aspectos medioambientales, como los económicos y sociales, tal y como viene utilizándose desde la Declaración de Río.

El objetivo principal de este trabajo es el de hacer constar que, a juicio del autor, para que la «rehabilitación sostenible» se desarrolle como una alternativa económica real para el sector de la construcción (1), se han de remover una serie de limitaciones o barreras existentes y se ha de ordenar el proceso simultánea e integradamente en todos sus aspectos financieros, de gestión y participación, normativos y técnicos, e, interviniendo en ello todos los niveles de la Administración y la sociedad civil implicada en cada ámbito territorial. Con este fin se comentan dos experiencias previas desarrolladas bajo estas premisas de las que se puede desprender la serie de lecciones aprendidas, enumeradas en el apartado relativo a las «CONCLUSIONES FINALES». En su conjunto, estas lecciones constituyen un modelo de intervención y gestión, cuya vigencia se renueva tras la reciente aprobación de la Ley 8/2013 de rehabilitación, renovación y regeneración urbanas, y cuya puesta en práctica ayudará a hacer viable el desarrollo de operaciones de rehabilitación a gran escala.

Cabe indicar que el carácter singular de la tenencia de viviendas en España en relación a los países de nuestro entorno no permite la extrapolación directa de los modelos de gestión implantados en ellos (2) (3). Las actuaciones en los barrios de HLM (viviendas de bajo alquiler) en Francia, o los planes de rehabilitación y renovación urbana de las viviendas de la antigua República Democrática de Alemania, por ejemplo, se llevan a cabo sobre un parque residencial de propiedad mayoritariamente pública. Ello origina unos procesos de gestión institucional directa, de implantación más sencilla que en el caso español. La vivienda en régimen de propiedad horizontal en España es ampliamente dominante y ello redunda en mayores dificultades en relación a la gestión y financiación de estos procesos.

El espacio disponible para ello no permite tratar en profundidad todos los datos técnicos y ambientales de las experiencias que se acompañan, por lo que su descripción se reduce a aquellos que se entienden como estrictamente necesarios para la comprensión de la importancia que aquí se confiere a los aspectos de la participación y la gestión, como el propio título indica. Estos datos técnicos y medioambientales se desarrollan más ampliamente en los documentos de referencia (4) (5) (6) (7), a los que remitimos a los lectores que lo deseen.

\section{DIMENSIÓN DEL PROBLEMA}

La rehabilitación de viviendas ha sido tradicionalmente un objetivo presente en los sucesivos planes de vivienda estales y autonómicos desde los años 80. Pese a ello, su incidencia en el sector de la edificación no ha sido comparable con el volumen de negocio movido por la ejecución de edificios de nueva planta. La magnitud del problema actual arroja la cifra de 5,48 millones de edificios residenciales y de 9,73 millones de viviendas principales construidas con anterioridad a 1980 (8), fecha que se considera representativa para medir la demanda potencial de la rehabilitación, puesto que en 1979 entró en vigor la primera Norma Básica de ahorro energético.

Gran parte de estos edificios y viviendas se sitúan en Grandes Conjuntos Urbanos de bloque abierto, construidos entre los años 40 y 80 , que se ubican en las periferias urbanas, y que constituyen el objeto de este artículo. Actualmente muchos de ellos se encuentran degradados o son vulnerables física y socialmente (9) (10). Únicamente en el municipio de Madrid se incluyen 330 polígonos de bloque abierto en estas circunstancias, que albergan 491.000 viviendas (el $36 \%$ del parque residencial) y 1.228.00o habitantes (el $38 \%$ de la población) (11). Estos polígonos, como los del resto de España, fueron construidos en ausencia de una normativa básica que reglamentara sus características técnicas y funcionales. Necesitan, por consiguiente, una urgente regeneración en la línea de la definición de rehabilitación sostenible dada más arriba. Entre otras intervenciones, ello implica la rehabilitación integral de su edificación, con el fin de lograr edificios eficientes y adecuados a unos estándares normativos propios del siglo xxI.

Por otra parte, España importa el 74 \% (12) de sus necesidades de energía primaria, y la factura anual de estas importaciones asciende a 57.486 millones de euros (13). Los hogares españoles consumen el $17 \%$ de toda la energía final (14), por lo que únicamente dando cumplimiento a la Estrategia EUROPA 2020 (15) (reducción emisiones de gases de efecto invernadero en un $20 \%$ respecto a los niveles de 1990; aumento del $20 \%$ de energías renovables y reducción del $20 \%$ del consumo energético), nuestro país dispondría de no menos de 1.955 millones de euros adicionales anualmente, que bien podrían reinvertirse en mantener a largo plazo un proceso sostenido y sostenible de la rehabilitación del parque edificado.

\section{CONTEXTO ACTUAL}

\subsection{Barreras a la rehabilitación}

En la actualidad existe una serie de barreras que dificultan la puesta en marcha de intervenciones que cuenten con la certeza sobre su viabilidad, la escala y el volumen de negocio necesarios para que resulten rentables y constituyan un motor económico real (16).

Estas barreras son de diferentes índoles: legislativas, normativas, urbanísticas, productivas y tecnológicas, organizativas y de gestión, formativas, sociales y financieras (17). Tanto las barreras legislativas como las organizativas y de gestión han sido solventadas en gran medida con la aprobación reciente de la Ley 8/2013, de 26 de junio, de rehabilitación, regeneración y renovación urbanas (LRRRU), y del Real Decreto 233/2013, de 5 de abril, por el que se regula el Plan Estatal de fomento del alquiler de viviendas, la rehabilitación edificatoria, y la regeneración y renovación urbanas, 2013-2016 (PARRRU). Ello genera nuevas oportunidades para el desarrollo de las actuaciones de rehabilitación, como más adelante se verá.

Sin embargo, muchas de las restantes barreras perviven todavía, siendo las más importantes las de índole social y las de índole financiera.

En cuanto a las primeras, los Grandes Conjuntos Urbanos están habitados mayoritariamente por grupos sociales vul- 
nerables de recursos limitados (18). Se requiere caracterizar socio-económicamente estas poblaciones, y elaborar modelos de participación ciudadana y gestión adecuados.

En cuanto a las segundas, cabe indicar que la actividad directa e inducida por la rehabilitación genera tasas de retorno ampliamente favorables para las administraciones. Esta tasa de retorno proviene de la recaudación de impuestos (IVA, Sociedades, IRPF, incremento del IBI), de la captación de cuotas a la Seguridad Social y de la reducción de los subsidios de desempleo. La actividad inducida por la rehabilitación coadyuva notablemente al incremento de esta tasa de retorno (19). Pese a ello, y a que las familias hoy no cuentan con capacidad de endeudamiento, las políticas basadas en la inversión pública están en entredicho. Por otra parte, se pueden poner en valor recursos ociosos del propio territorio, fomentando la inversión privada. Entre estos recursos no explotados podemos indicar, entre otros, los siguientes:

- La capitalización del ahorro y/o la producción energética (rehabilitación energética de edificios, energías renovables, «district heating», ...).

- La capitalización de los ahorros de emisiones de Gases de Efecto Invernadero $\left(\mathrm{CO}_{2}, \ldots\right)$.

- La instalación de nuevos usos y/o equipamientos (aparcamientos subterráneos, empresas, ...).

- La explotación de los incrementos de edificabilidad (nuevas viviendas, ...).

En cualquier caso, la función de las administraciones públicas como motores y garantes de las intervenciones, y su apoyo financiero a los más vulnerables, no puede ser eliminada ni restringida. La Política de Cohesión de la UE prevé nuevas modalidades de aplicación de los Fondos Estructurales que los incorporan de forma unificada con el objetivo de lograr un Desarrollo Urbano Sostenible e Integrado (20), lo que constituye una oportunidad que no debería ser desaprovechada.

\subsection{Nuevas oportunidades para la rehabilitación}

La actual coyuntura legislativa de las administraciones españolas y de la Unión Europea plantea obligaciones y oportunidades, que pueden cambiar las perspectivas de financiación de actuaciones de desarrollo urbano integrado en nuestro país.

La Directiva de Eficiencia Energética 2012/27/UE, en su Capítulo II sobre «Eficiencia del Uso de Energía», Artículo 4 exige que los «Estados miembros establezcan una estrategia de renovación del parque edificado publicando una primera versión antes del 30 de abril de 2014».

La Estrategia Europa 2020 plantea el logro de objetivos concretos como son el «empleo, la reducción de emisiones, el aumento de energías renovables y de la eficiencia energética (20-20-20), así como la lucha contra la pobreza y la exclusión social, entre otros. La Política de Cohesión 2014-2020 es la vía para potenciar la cohesión económica y social en la UE, con inversiones apoyadas por los Fondos Estructurales. Esta política dispone de nuevos medios técnicos y de gestión para el logro de este fin, como son:

- El Desarrollo Urbano Sostenible Integrado: renovación física de las ciudades combinada con la promoción de la educación, el desarrollo económico, la inclusión social y la protección del medio ambiente.
- La Inversión Territorial Integrada (ITI): mecanismo para formular respuestas integradas a las necesidades territoriales.

- El Desarrollo Local a cargo de las Comunidades Locales: desarrollo urbano por medio de la cooperación entre los ciudadanos locales, la sociedad civil, la economía local y los diversos estamentos gubernamentales.

El uso de estos medios permitirá incorporar de forma unificada en proyectos integrados los diferentes Fondos (Fondo Social Europeo, Fondo Europeo de Desarrollo Regional, Fondo de Cohesión, Fondo Europeo Agrícola y de Desarrollo Rural, y Fondo Europeo Marítimo y de la Pesca). La asignación de los Fondos Europeos a estas actuaciones no podrá superar el 50\% del total de la inversión en las regiones más desarrolladas, el $60 \%$ en las regiones en transición y el $75 \%$ en las regiones menos desarrolladas. El resto deberá ser aportado por las administraciones españolas y los beneficiarios.

La asignación a España de Fondos Estructurales de la UE asciende a 28.560 millones de euros (21). A lo largo del año 2014 se ha aprobado el «Programa Operativo» (13) español para el desarrollo de los compromisos nacionales y regionales respecto a esta estrategia.

Como ya se ha comentado, el Estado dispone actualmente de la nueva Ley y el Plan Estatal de rehabilitación. En el aspecto relativo a la gestión, la Ley abre la vía para la creación de Asociaciones Administrativas que operen como entidades de gestión en los Ámbitos de Regeneración y Renovación Urbana, y que permitan la participación ciudadana organizada en la toma de decisiones, de forma igualitaria con las administraciones competentes. En el aspecto relativo a las ayudas, se destinan importantes subvenciones de hasta el 40\% del coste de las actuaciones en la Rehabilitación Edificatoria, los Ámbitos de Regeneración y Renovación Urbana y el Fomento de Ciudades Sostenibles y Competitivas (22).

Estas ayudas serán complementarias a las que, en su caso, aprueben las Comunidades Autónomas que preparen sus propios Planes, equivalentes al estatal. La firma de los Convenios Bilaterales entre las CCAA y el Ministerio de Fomento permitirá el desarrollo del Plan Estatal. En los aspectos técnicos, algunas CCAA han elaborado Planes estratégicos, Inventarios de Barrios, etc. para determinar sus prioridades de actuación, y en el aspecto urbanístico deberían estar definiendo los objetivos y contenidos de nuevas figuras de planeamiento acordes con la intervención en el medio urbano consolidado (23)

\section{PLANTEAMIENTO GENERAL DE LA SOLUCIÓN}

El modelo de rehabilitación propuesta tiene tres funciones esenciales que, en opinión del autor, se ligan directamente con cada uno de los aspectos de la sostenibilidad buscada: mejorar la calidad de vida de las personas (sostenibilidad social y mejora de la cohesión), invertir en el futuro del país reduciendo los sobrecostos generados por una edificación ineficiente (sostenibilidad ambiental) y contribuir al desarrollo económico generando actividad y empleo (sostenibilidad económica).

Las futuras intervenciones deben integrar los aspectos urbanos, técnicos, sociales, de gestión y formativos, deben plantearse considerando, de forma simultánea y unificada, la pla- 
nificación técnica, la participación ciudadana, la estructura de gestión y la viabilidad financiera. Ello implicará a todos los niveles administrativos y territoriales.

La puesta en marcha de operaciones de rehabilitación y regeneración de Grandes Conjuntos Urbanos permitirá que las viviendas potencialmente demandantes de rehabilitación cuantificadas más arriba, pasen a constituir una demanda realmente activa. Para ello se debe constituir un proceso que, mediante el liderazgo de las administraciones, supere las limitaciones existentes e incentive, ordene y sistematice el modelo de intervención. Estos procedimientos, deben, por un lado, preservar los derechos de los residentes y fomentar su participación en la toma de decisiones, y, por otro, crear modelos de negocio atractivos para el sector privado.

Los objetivos de este nuevo modelo, son, por tanto, los siguientes (24):

- Aumentar la escala de los ámbitos de rehabilitación, tanto en cuanto al número de viviendas como al espacio libre. Se ha de superar el ámbito de la comunidad de propietarios, promocionando fases de actuación en torno a los centenares de viviendas.

- Elevar el volumen de inversión en las actuaciones, adecuando los edificios existentes a unos requisitos funcionales equivalentes a los exigibles para la nueva edificación. Ello elevaría los presupuestos de rehabilitación al orden del $50 \%$ del valor de reposición de los inmuebles.

- Generar un modelo mixto de inversión, reduciendo la participación porcentual de las aportaciones de la administración española y de los residentes. Para ello se han de utilizar las crecientes oportunidades de financiación en el marco europeo, y proceder a la puesta en valor de los recursos no explotados de los ámbitos, lo que atraerá la inversión privada.

- Crear estructuras mixtas público-privadas que permitan garantizar la agilidad en la toma de decisiones, que coadyuvará a la entrada del capital privado.

En estas condiciones, las operaciones de regeneración integrada de Grandes Conjuntos Urbanos pueden dar lugar a inversiones totales absolutas próximas a los 50.000 euros por vivienda (4), que, según datos elaborados por el autor, son capaces de crear no menos de 15 empleos directos por millón invertido, de optimizar los recursos asistenciales, de originar procesos de formación especializada, de generar retornos a las administraciones del 50\% de la inversión (IVA, IRPF, Impuesto de Sociedades, Cuotas de la SS, reducción de Subsidios de desempleo, IBI, etc.). Por otra parte, se estimaciones que la actividad complementaria inducida es 4-5 veces superior a la directa de inicio de estos procesos (19).

En resumen, la rehabilitación de Grandes Conjuntos urbanos, así entendida, es sostenible y, en consecuencia, rentable para el país en términos económicos, sociales, de actividad, de empleo y de ahorro.

\section{DOS EXPERIENCIAS DE INTERVENCIÓN EN GRANDES CONJUNTOS URBANOS}

El autor de este artículo ha venido desarrollando su actividad profesional durante más de 30 años en la rehabilitación de Grandes Conjuntos Urbanos, siguiendo las líneas y criterios enunciados más arriba. Cabe reseñar dos experiencias en las que la integración de los aspectos sociales, técnicos y de gestión ha permitido superar gran parte de las barreras existentes.

Una es la «Rehabilitación Integral del Poblado Dirigido de Caño Roto en Madrid» (5), desarrollada entre los años 1992 y 1998, y en la se integraron de forma unificada los aspectos técnicos, los procedimientos metodológicos, de gestión y de participación ciudadana.

Otra es el «Programa Municipal de Rehabilitación de los Conjuntos Urbanos Edificados en Zaragoza entre 19451965», dirigido como técnico de la administración desde la Sociedad Municipal Zaragoza Vivienda por Juan Rubio del Val, y coordinado técnicamente a lo largo de todo el proceso por el firmante de este artículo entre 2004 y 2011.

La Oficina Técnica de Rehabilitación Urbana de Zaragoza, constituida por la empresa pública Zaragoza Vivienda estaba incluida en la Red Territorial Integrada de Oficinas Técnicas y de Gestión de la Comunidad Autónoma de Aragón.

\section{REHABILITACIÓN INTEGRAL DEL POBLADO DIRIGIDO DE CAÑO ROTO EN MADRID}

\subsection{Antecedentes}

El Poblado Dirigido de Caño Roto, proyectado por los arquitectos José Luis Íñiguez de Onzoño y Antonio Vázquez de Castro, fue promovido al inicio de los años 6o. Se construyeron 1.606 viviendas: 1.004 en edificios en altura y 602 en conjuntos unifamiliares. El trazado del Poblado responde a un modelo racionalista abierto, con espacios públicos de escala adecuada (Figura 1).

Los edificios en altura se agrupan en tres tipos diferentes:

- Bloques adosados: 29 portales con un total de 232 viviendas de $80 \mathrm{~m}^{2}$.

- Bloques en torre: 27 portales con un total de 324 viviendas de 63-74 $\mathrm{m}^{2}$.

- Bloques en dúplex: 14 portales con un total de 448 viviendas de 80-99-110 $\mathrm{m}^{2}$.

El sistema constructivo de todos los edificios es común: estructura de hormigón armado, con vigas de canto de sección $55 \times 12 \mathrm{~cm}$., vista al exterior; paños de fachada enrasados con los marcos de estructura, de ladrillo silico-calcáreo; y cubierta plana a la catalana (25). Las viviendas unifamiliares se construyeron con muros de carga del mismo ladrillo, con las plantas bajas asentadas sobre soleras y disponen de patios posteriores privados.

El diagnóstico de los problemas, la patología y las inadecuaciones de la edificación se realizó basándose en el conocimiento que el equipo técnico poseían del barrio como asesores de la Asociación de Vecinos, así como en la información contenida en el «Estudio del Estado Actual del Poblado Dirigido de Caño Roto», realizado en 1992-1993 por la UTE Aroca Asociados y Euroconsult.

Los problemas que afectan a los elementos comunes de los edificios multifamiliares se corresponden con la inseguridad en las estructuras y algunas cimentaciones, la degradación de los materiales, la lógica inadecuación a los requisitos técnicos 


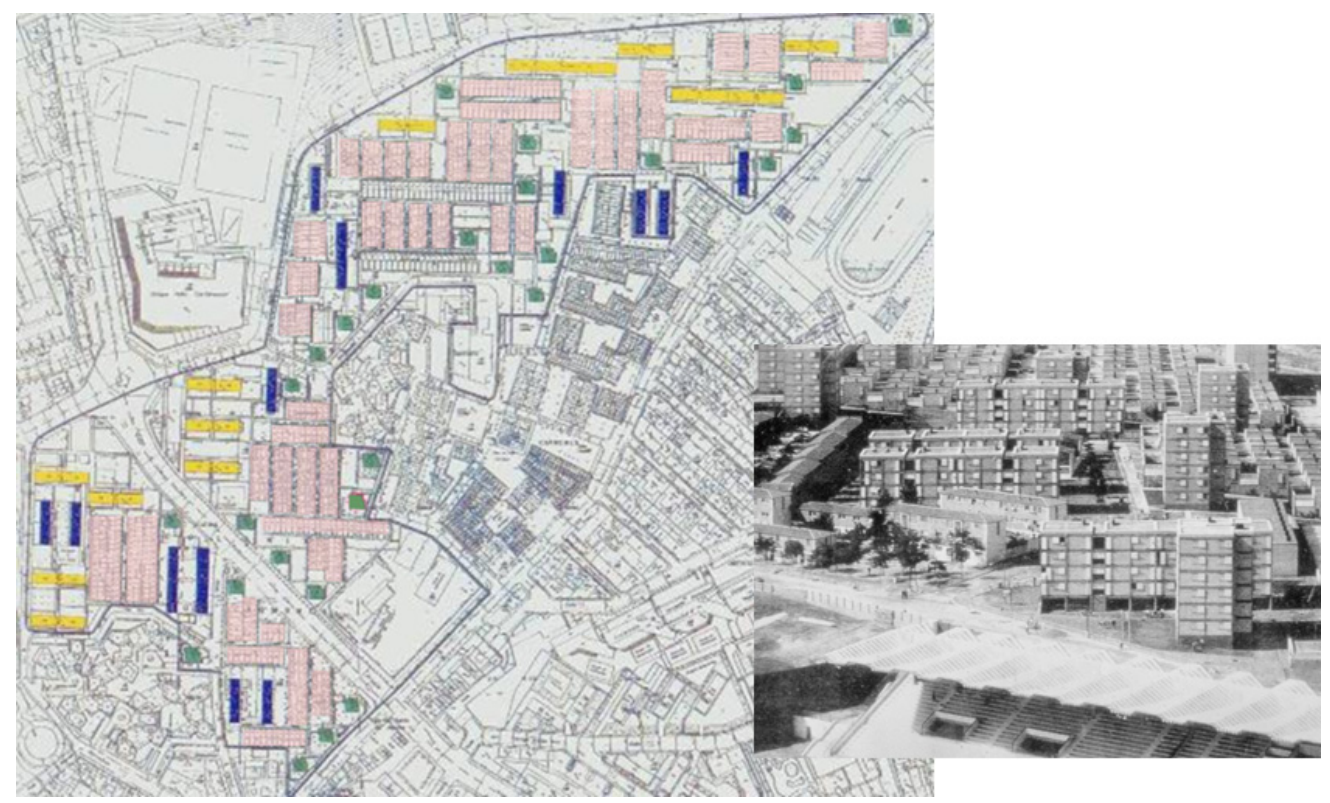

Figura 1. Situación, emplazamiento y vista de los edificios en el Poblado Dirigido de Caño Roto (plano de elaboración propia y fotografía aérea del Ayuntamiento de Madrid).

de los años 90, la existencia de barreras arquitectónicas y el desorden de los huecos y contraventanas, como consecuencia de las modificaciones realizadas por los vecinos.

La resolución de los problemas en las viviendas unifamiliares presentaba una mayor dificultad por los arreglos y ampliaciones realizadas por los vecinos, y por la inexistencia de comunidades de propietarios, pese a existir elementos comunes y afecciones mutuas entre ellas.

Las condiciones de habitabilidad de las viviendas y restantes elementos privativos eran muy adecuadas. La casi totalidad estaban actualizadas presentando un estado satisfactorio. Únicamente un número reducido de situaciones de precariedad social requería la intervención sobre los elementos privativos para dotarlos de las mínimas condiciones de habitabilidad.

Por consiguiente, la intervención incidió sobre la adecuación estructural y funcional de los elementos comunes, e incluyó cuantas acciones fueron necesarias para logar su máxima adecuación a la normativa vigente en el momento de llevarse a cabo la rehabilitación para una edificación equivalente de nueva planta.

En resumen, éstas fueron: la reparación y refuerzo de estructuras y cimientos, la mejora de los accesos, la adecuación de las condiciones de estanqueidad, de las instalaciones y de los servicios generales, la mejora de la seguridad frente a accidentes y siniestros, y, muy especialmente, la mejora integral de la eficiencia energética de los edificios (incluyendo el doblado de carpinterías y la instalación de nuevas contraventanas mallorquinas y devolviendo a las fachadas un lenguaje arquitectónico ordenado), así como la supresión de barreras arquitectónicas, incluyendo la instalación de ascensores en los edificios que así lo solicitaron.

\subsection{Gestión y participación ciudadana}

El Ministerio de Obras Públicas, Transporte y Medio Ambiente, la Comunidad Autónoma y el Ayuntamiento de Ma- drid firmaron un Convenio para la Rehabilitación del Poblado Dirigido de Caño Roto en mayo de 1994, una vez declarado Área de Rehabilitación Preferente. Como tal le correspondieron las siguientes subvenciones:

- $30 \%$ del coste total de la actuación, concedida por el MOPTMA.

- 20 \% del presupuesto de la actuación, concedida por la Comunidad Autónoma de Madrid, con un límite de 400.000 pesetas por vivienda, que en la actual moneda Euro representan aproximadamente 2.400 euros.

El resto de las aportaciones económicas fueron realizadas por los propietarios, que pudieron solicitar préstamos cualificados.

En el mes de julio de 1994 se constituye ante notario la Entidad Gestora para la Rehabilitación del Poblado Dirigido de Caño Roto, constituida por la Comunidad Autónoma y el Ayuntamiento de Madrid, y los propietarios de viviendas del barrio. La adhesión de éstos fue paulatina a lo largo del desarrollo de las actuaciones, hasta alcanzar la totalidad de los vecinos de los edificios en altura y la mitad de los de viviendas unifamiliares. Esta adhesión exigía la firma individual de los estatutos, derechos y compromisos, particularmente los financieros.

Tal Entidad se inscribió en un Registro de la Consejería de Política Territorial de la Comunidad Autónoma de Madrid (CAM) creado al efecto en octubre, constituyéndose el Consejo Rector con tres representantes de las administraciones y tres representantes de los propietarios. Fue presidida por la representante de la CAM, y asesorada, con voz y sin voto, por la Asociación de Vecinos, la empresa de gestión, y el equipo de arquitectos.

La Entidad Gestora tenía capacidad para gestionar la totalidad del proceso, particularmente su secuencia, la formación de fases de obra, las bases y convocatorias de los concursos, las contrataciones y la viabilidad financiera. La gestión económica global del proceso incluyó la percepción de subven- 
ciones en nombre de los afiliados y la recepción adelantada a cuenta de aquellas del 5-10\% del presupuesto. Ello permitió el inicio de las actuaciones al financiarse así los estudios técnicos previos, los honorarios de la empresa de gestión, los proyectos básicos según tipologías de la edificación, una campaña de difusión sistemática y la documentación resumida necesaria para ello. Ésta contenía imágenes finales de la rehabilitación, el diagnóstico de los problemas y soluciones, el presupuesto de cada modelo tipológico y la propuesta financiera.

Esta campaña permitió un rápido incremento de las adhesiones de los interesados, dando lugar a la definición de las fases de desarrollo de las actuaciones, de forma tal que cada fase incluía los edificios en que el $90 \%$ de los propietarios estuviera adherido a la Entidad Gestora

\subsection{Replicabilidad del método}

La rehabilitación del Poblado Dirigido de Caño Roto presenta una elevada eficacia en el cumplimiento de sus objetivos, con los siguientes resultados:

De las 1.004 viviendas, situadas en edificios, y las 602 viviendas unifamiliares con que cuenta, se rehabilitaron integralmente la totalidad de las primeras y más de 350 unifamiliares (en total unas 1.350 viviendas) en cinco fases anuales entre 1994 y 1998. El desarrollo temporal fue el siguiente:

- Entre 1992 y 1994 se realizaron los trabajos previos y los procesos de difusión y participación.

- En 1994 se ejecuta una $1^{\circ}$ fase de 40 viviendas.

- Entre 1995 y 1998 se pusieron en marcha cuatro fases de 330 viviendas aproximadamente.

En la Figura 2 se muestran las imágenes de los edificios previas y posteriores a la rehabilitación.

El procedimiento de gestión seguido se ha demostrado esencial para explicar los logros obtenidos. El desarrollo real de esta experiencia ha originado una serie de lecciones aprendidas, que se resumen más adelante, en el apartado de las Conclusiones; y, por otra parte, los contenidos de la nueva Ley de rehabilitación, renovación y regeneración urbanas coadyuvan a la puesta en marcha de operaciones de una escala análoga. Todo ello permite pensar que, en el caso de tenerse en cuenta tales lecciones aprendidas, el método seguido puede ser generalizado con éxito en intervenciones futuras a lo largo de todo el Estado.

\section{PROGRAMA MUNICIPAL DE REHABILITACIÓN DE CONJUNTOS URBANOS EN ZARAGOZA}

\subsection{Antecedentes}

Si la experiencia de la Rehabilitación del Poblado Dirigido de Caño Roto constituyó un modelo en cuanto a su eficacia, sin duda derivada de su proceso de participación- gestión, la del Programa Municipal de Rehabilitación de los Conjuntos Urbanos de la Posguerra en Zaragoza constituyó también un modelo en cuanto a la calidad constructiva y formal de los resultados obtenidos en el desarrollo de sus Proyectos Piloto. De hecho, el Programa de Zaragoza es, en gran medida, un resultado directo de la aplicación sistemática del método y las lecciones aprendidas durante la rehabilitación de Caño Roto.

Como indicativo de la calidad alcanzada por el Programa de Zaragoza se puede indicar la consecución de los siguientes premios nacionales e internacionales:

- Selección como una de las 100 Mejores Prácticas mundiales en 2010 por HABITAT-ONU.

- Premio a la Mejor Rehabilitación, concedido por la Asociación de Promotores Públicos de Vivienda (AVS) en 2010.

- Premio a la Rehabilitación Más Sostenible, concedido por ENDESA en 2010.

La estrategia de la intervención planteada en Zaragoza pretendía sentar las bases para poder llegar a rehabilitar hasta 8.560 viviendas, organizadas en 21 Conjuntos Urbanos. La situación de estos Conjuntos en la ciudad es dispersa, su tamaño heterogéneo, su medio físico y social presentan características diferenciales y los trabajos de rehabilitación debían ser adjudicados mediante concurso a cuatro equipos técnicos diferentes. Salvando las lógicas diferencias de escala, el potencial planteamiento de la rehabilitación de Conjuntos Urbanos en todo el Estado presenta notables similitudes con esta estrategia.

La principal aportación del trabajo desarrollado en el Programa Municipal de Rehabilitación de los Conjuntos Urbanos de la Posguerra en Zaragoza es el de contar con un método propio, pero de aplicación general, basado en el tratamiento sistemático e interactivo de la recogida de información física y social, del diagnóstico de los problemas, de las propuestas de intervención, de los cauces de participación ciudadana, de los procesos en la toma de decisiones, de la constitución de las estructuras organizativas y de gestión, y de los medios de financiación (4) (6) (26) (27).

Las mejoras obtenidas en el aspecto relativo a la sostenibilidad ambiental de las actuaciones se reflejan en (6), y han sido objeto de un análisis posterior desarrollado en (7).

\subsection{Clasificación sistemática de la edificación}

Se ordenaron los edificios existentes según un sistema de categorías, modelos y tipos. Los orígenes, diseños y tecnologías constructivas de la edificación de los 21 Conjuntos constituyen un universo relativamente homogéneo, pese a su aparente heterogeneidad. En función de ello, la edificación se pudo dividir en una serie jerárquica y reducida de:

- Categorías y Modelos de edificios.

- Tipos y códigos de portales.

Cada categoría estaba formada por todos aquellos edificios que tienen en común su época de diseño y ejecución y su entidad promotora. La constitución de una categoría no se relaciona estrictamente con su fecha real de diseño o construcción, sino con la del modelo productivo y el objetivo promocional en que se integra. Las categorías se dividen en modelos, determinados por la conformación formal y funcional de los edificios y las viviendas, su tecnología, sistemas constructivos y materiales, y cuantas otras características permitían su conceptualización unitaria. 

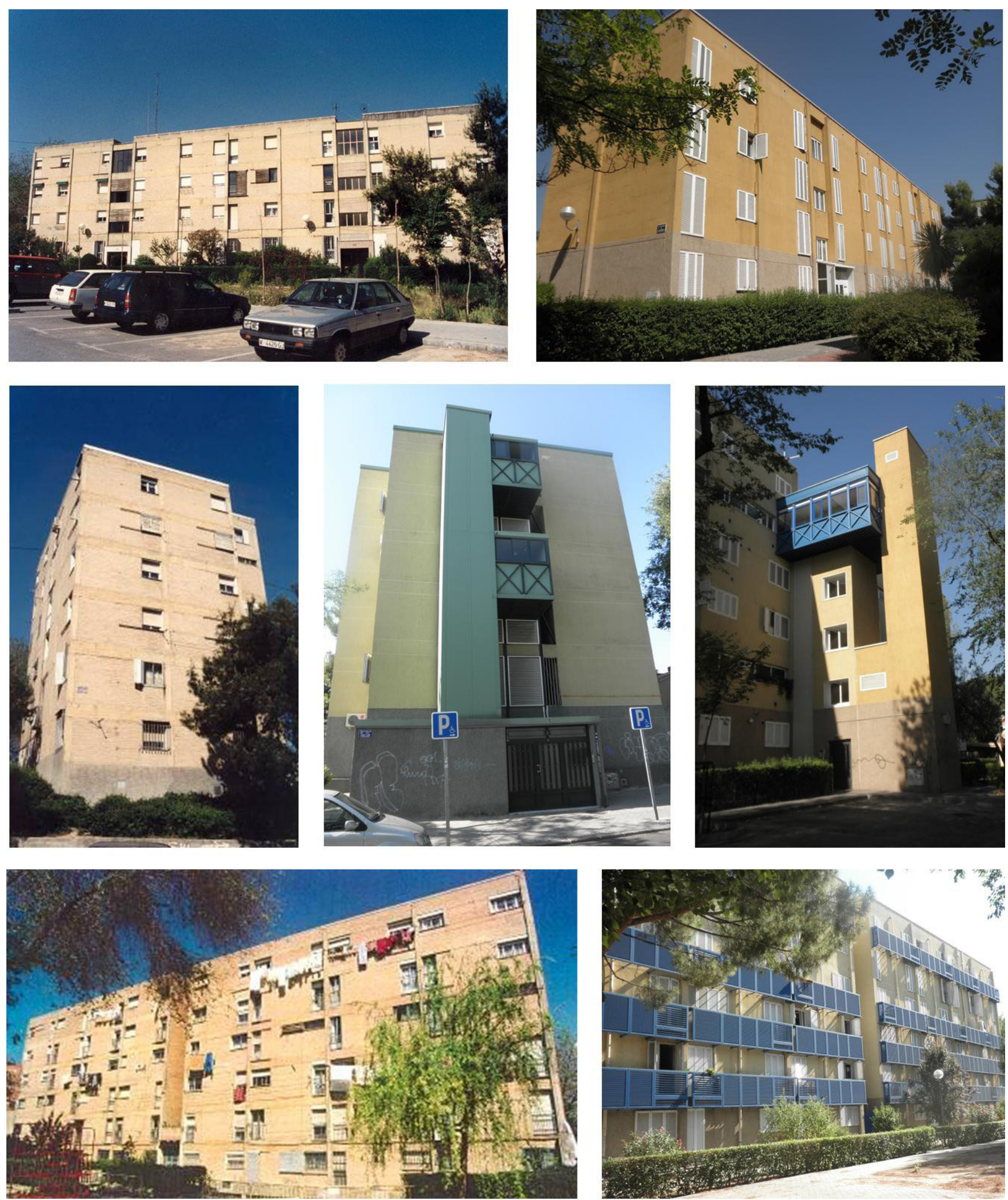

Figura 2. Imágenes de los edificios antes y tras la rehabilitación en el P.D. de Caño Roto (fotografías tomadas por el autor).

Sirvan como ejemplo para su potencial generalización, las categorías aquí consideradas, que fueron las siguientes:

- Edificios de la Autarquía. Arquitectura de la inmediata posguerra, en la década de los años 40, construida sin acero y bajo promoción estatal (Regiones Devastadas...).

- Viviendas Unifamiliares. Arquitectura de carácter rural, de las décadas de los años 40 y 50 de promoción estatal
(Instituto de Colonización, ...) dirigida al asentamiento de inmigrantes rurales en las ciudades. Viviendas agrupadas y con parcela propia.

- Edificios de Viviendas Baratas Sociales. Arquitectura del final de la Autarquía, al amparo de la Ley de Vivienda de Renta Limitada de 1954, de promoción pública (Obra Sindical del Hogar, Instituto de la Vivienda, ...) o privada sin ánimo de lucro (grandes empresas, obra social de la Igle- 
sia). Modelos muy homogéneos de cuatro a cinco plantas, escalera central y dos viviendas por planta.

- Edificios de Viviendas Baratas de Iniciativa Privada. Arquitectura de promoción privada con ánimo de lucro, de la década de los años 60, tras los primeros Planes de Desarrollo. Mayor variedad de modelos con carácter especulativo, edificios de mayor altura y agrupaciones diversas.

- Edificios de Viviendas de Categoría Media. Arquitectura Internacional, propia del desarrollo de la década de los años 70, de promoción privada especulativa dirigida a las clases medias de la población.

La división en los diferentes Tipos de los distintos portales existentes en cada modelo (con sus Códigos identificativos asociados unívocamente) se realizó siguiendo un criterio meramente geométrico-cuantitativo. Su objetivo fue el de permitir una rápida medición de las soluciones constructivas para obtener una valoración suficientemente aproximada de las actuaciones. Esta definición geométrica permitió elaborar una ficha por cada tipo cuyo tratamiento conllevó el desarrollo de una aplicación informática específicamente elaborada para este Programa.

El desarrollo técnico de estos aspectos, y de cuantos siguen a continuación, pueden ser consultados en las referencias (4) (6) (23) (28).

\section{7•3. Inadecuación de la edificación a la normativa vigente}

El criterio de calidad establecido asumía que la rehabilitación tenía como fin la completa adecuación de los edificios a la normativa vigente en el momento de la rehabilitación para una obra nueva equivalente. Se recopiló la normativa procedente todos los niveles administrativos que era de aplicación al caso. Se elaboraron fichas de las características constructivas de las categorías y modelos desde la óptica de su potencial inadecuación a la normativa anterior, y, en consecuencia, de los objetivos de la rehabilitación para dar cumplimiento a aquella en cada una.

\subsection{Tipificación de los problemas y del diagnóstico de la edificación}

Una misma época de edificación implica la homogeneidad de los riesgos patológicos y de las carencias derivadas de su diseño, ejecución, implantación en un medio ambiente común y deficiente mantenimiento. En consecuencia, se produce una degradación paralela de la edificación, que permite una fácil tipificación sistemática de los problemas y sus soluciones. Tal tipificación se adecúa a su tratamiento informático, elaborando una base de datos de los sistemas y elementos que conforman la edificación y de los listados de los problemas tipo asociados a ellos.

\subsection{Tipificación de las soluciones y de las propuestas de actuación. Base de precios}

El número y tipo de soluciones constructivas viables que existen en el mercado para los problemas detectados era, y sigue siendo, limitado y fácilmente definible. Tales soluciones o propuestas de actuación tipo se organizaron en otra base de datos de las posibles soluciones, asociada a una base de precios paralela. Se elaboró una aplicación para asignar las soluciones deseadas a cada unidad de intervención y calcular automáticamente el presupuesto de la rehabilitación, que incluía, tanto los costes directos como los indirectos previsibles (informes, honorarios técnicos y de gestión, gastos sociales, urbanización, impuestos, etc.).

\subsection{Caracterización socio-económica de la población de los Conjuntos Urbanos}

El análisis socio-económico de la población de los Conjuntos, desveló un perfil mayoritario, que, salvando las diferencias locales y de escala, también presenta notables similitudes con el esperable en el resto de los Grandes Conjuntos Urbanos de todo el Estado.

Se trataba, en general, de una población de las siguientes características:

- Mayor edad media que la de la ciudad de Zaragoza (21 \%-53 \% de los habitantes eran mayores de 65 años frente al $18 \%$ total en Zaragoza). Como consecuencia, la tasa de dependencia era muy elevada, abundaban las parejas ancianas o las viudas, y las viviendas tenían una ocupación baja.

- Presentaba un alto índice de la población extranjera (10 \%-17 \% de extranjeros frente al 6,6 \% total de Zaragoza), en gran medida en situación de precariedad económica y laboral.

- La población contaba con escasos recursos sociales, culturales y económicos (niveles muy inferiores a la media de la ciudad). Se trata de una capa de población poco formada y económicamente desfavorecida, con reducidos porcentajes de población activa, trabajadores poco cualificados, y altas tasas de paro y precariedad.

- La población estaba poco estructurada y era poco participativa y reivindicativa. Muchas fincas no contaban siquiera con comunidad de propietarios, y el tejido asociativo era escaso, débilmente implantado y con una capacidad de movilización reducida.

\subsection{Participación ciudadana}

La creación de una malla asociativa con unas características adecuadas al fin propuesto constituyó un objetivo prioritario de este trabajo. Se fomentó el desarrollo de las asociaciones existentes y se formaron órganos vecinales representativos en los edificios en rehabilitación, con los siguientes objetivos y características:

- Adecuarse a las capacidades y habilidades sociales de la población.

- Tener suficiente capacidad para recabar de la administración toda la información disponible sobre el proceso y para difundirla entre la población.

- Insertarse en un modelo de gestión creado con el fin de lograr su participación activa en la toma de decisiones colectivas.

\subsection{Implantación del modelo de gestión}

El éxito de la operación tuvo su razón de ser en la creación de un proceso basado en el apoyo permanente en los aspectos de la gestión, dado a los habitantes desde la administración local, y en los aspectos económicos, desde las tres administraciones (local, regional y estatal) (4) (27) (28). 
Tras una fase previa, en que se desarrolló el método antes descrito, se procedió a la selección de cuatro proyectos piloto (Figura 3).

Esta selección se desarrolló en dos fases sucesivas. En la primera de ellas, la propia administración local (Sociedad Municipal Zaragoza Vivienda) decidió seleccionar cuatro de los 21 Conjuntos Urbanos objeto del estudio anterior (6) que reunieran las dos condiciones siguientes:

- Estar equilibradamente repartidos en el ámbito de la ciudad, y

- Ser claramente representativos de las condiciones físicas y sociales de todos los Conjuntos, una vez analizados los resultados del estudio.

En la segunda fase se convocó un Concurso de adjudicación de subvenciones extraordinarias a las comunidades de propietarios que resultasen ganadoras para la redacción de proyectos y la ejecución de obras de rehabilitación piloto. Las condiciones de este concurso se indican más adelante.

En el año 2006 se creó una Oficina de Coordinación y Gestión Técnica (OCGT) de las Áreas de Rehabilitación Integral de Picarral, Delicias, Las Fuentes y San José, con el fin de promover la rehabilitación entre los beneficiarios y de desarrollar cuantas actividades de comunicación, información y apoyo a la gestión de las actuaciones fueran necesarias durante todo el proceso, incluso la tramitación de las ayudas previstas.
Se formó un equipo mixto (técnicos y trabajadores sociales) de "gestión activa», cuyo personal se sometió a un curso intensivo de formación ajustado a los objetivos de los trabajos a desarrollar, impartido en tres bloques: diagnóstico y propuestas generales, normativa básica de aplicación y diagnóstico y propuestas específicas en las áreas.

La «gestión activa» se concibe en contraposición con la «gestión pasiva». En esta última las oficinas de rehabilitación actúan a la espera de que, por iniciativa propia, los posibles beneficiarios inicien las actuaciones. Esta "gestión pasiva» parece haber sido escasamente eficiente, dado que, conforme a las estadísticas del sector (29), el número de edificios y viviendas rehabilitadas en España en las últimas décadas es inferior a las cifras que arrojan los países de nuestro entorno. La gestión activa se basa en un trabajo sistemático de captación "puerta a puerta», «escalera a escalera», "edificio a edificio», «modelo edificatorio a modelo edificatorio» $\mathrm{y}$ «conjunto a conjunto», repartiendo folletos, constituyendo comunidades de propietarios, convocando y desarrollando juntas de vecinos, de tal forma que se genera la imprescindible comprensión y aceptación de la rehabilitación por parte de éstos.

La culminación de este proceso dio lugar a la convocatoria del Concurso antedicho para la adjudicación de subvenciones extraordinarias a las comunidades de propietarios para la redacción de proyectos y la ejecución de obras de rehabilitación piloto. Sus condiciones fueron las siguientes:

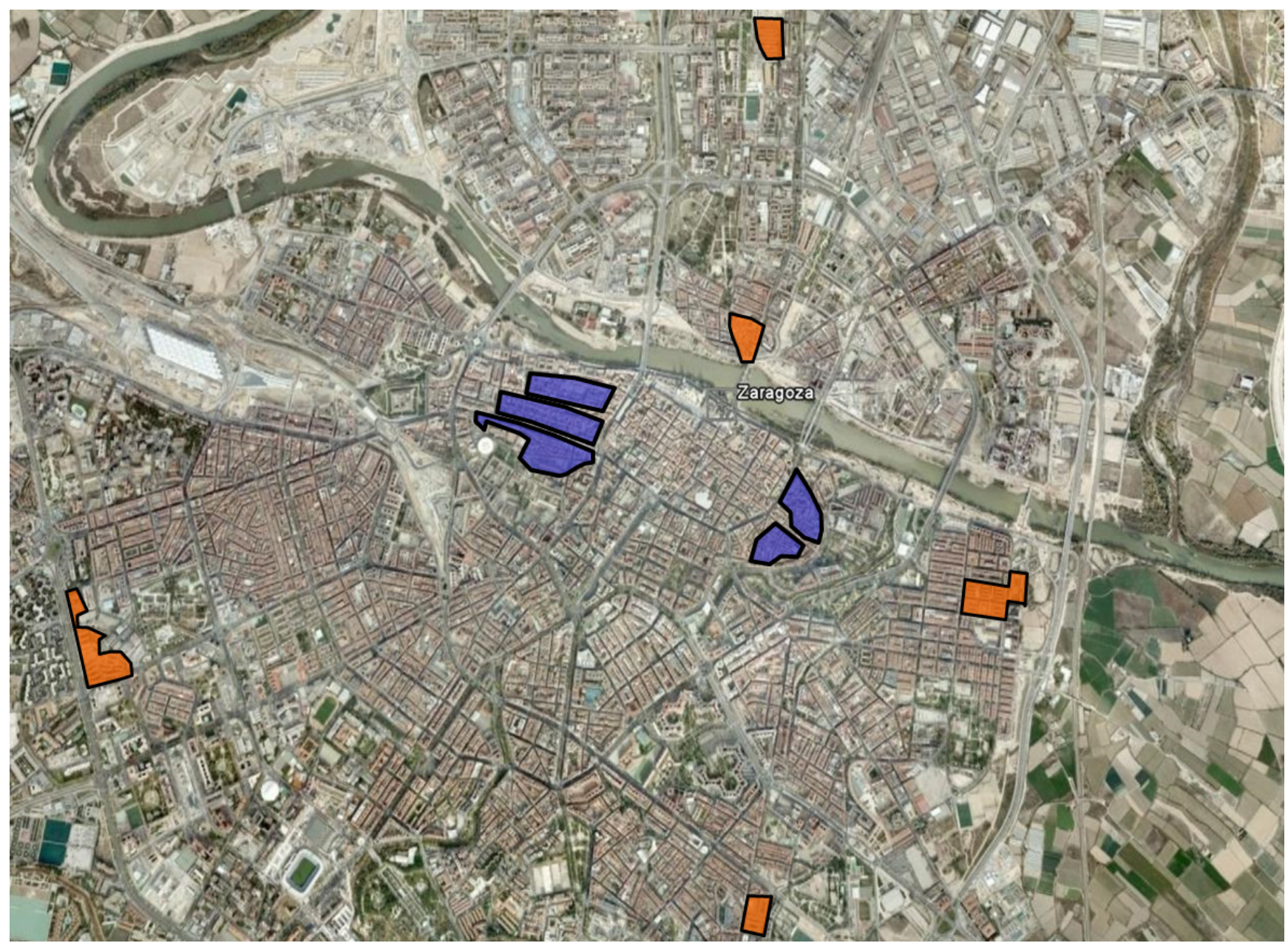

Figura 3. En color naranja: Situación de los Conjuntos Urbanos en que se realizaron los proyectos piloto (plano elaborado por el autor). 
1. Comunidades de propietarios constituidas.

2. Acuerdo amplio para la rehabilitación en cada comunidad. Se exigió un acuerdo mínimo del $60 \%$ de los titulares de las viviendas, con una puntuación exponencialmente creciente hasta un acuerdo del $100 \%$ de éstos.

3. Portales contiguos en un solo edificio. Máxima puntuación para edificios completos.

4. Acuerdo de conformidad de la comunidad con la propuesta técnica dada por Zaragoza Vivienda, con los marcos normativo y financiero, y con las subvenciones previstas.

En 2008 el Ayuntamiento de Zaragoza y el Gobierno de Aragón pusieron en marcha la Oficina Técnica de Rehabilitación Urbana de Zaragoza, lo que permitió la simplificación de los trámites, la gestión de ayudas, la elaboración de anteproyectos, proyectos, el seguimiento directo de la ejecución de las obras, etc.

Su gestión fue encomendada a la Sociedad Municipal Zaragoza Vivienda, en desarrollo de un Convenio de Gestión para estas Áreas, firmado por las tres administraciones. Esta Oficina contó con subsedes de proximidad en cada uno de los ámbitos, con el fin de dar asesoramiento inmediato a los vecinos.

El objetivo de esta Oficina era el de extender el modelo propuesto en los proyectos piloto a la totalidad de los ámbitos delimitados. Su personal se dividió en dos tipos de equipos multidisciplinares operativos.

- El Equipo de Valoración, responsable de los trabajos previos a la rehabilitación, desde la toma de contacto inicial, hasta el logro de acuerdos favorables por las comunidades de propietarios. Su trabajo concluía con la firma de un Convenio entre las comunidades y la Sociedad Zaragoza Vivienda.

- Los Equipos de Seguimiento, responsables del control de la elaboración y tramitación del proyecto de rehabilitación, del desarrollo de las obras, del control de las certificaciones y de la gestión de las ayudas económicas, hasta la liquidación final de las actuaciones.

El desarrollo de los proyectos y obras de estos edificios piloto dio lugar a los resultados que se muestran en las imágenes de la Figura 4.

\section{CONCLUSIONES FINALES}

Los procedimientos de actuación apuntados en las experiencias anteriores constituyen modelos experimentados y, por consiguiente, que pueden considerarse fiables, para lograr niveles de eficacia y calidad comparables en intervenciones análogas. Para que ello sea posible deben tenerse en cuenta las siguientes lecciones aprendidas de ellas:

1. La población debe estar estructurada para el objetivo de la rehabilitación. De no ser así, habrá de procederse a crear tal estructura, en la que las asociaciones de vecinos juegan un papel decisivo.

2. La Administración debe liderar el proceso, particularmente en sus fases iniciales, avanzando las primeras subvenciones, y resolviendo los problemas de la población en situación de precariedad social o económica.

3. Es preciso crear Entidades de Gestión mixtas público-privadas que integren a todos los agentes con intereses en el territorio (administraciones, ciudadanos locales, asociaciones de todo tipo de la sociedad civil, sectores presentes de la economía local), y estén dotadas de capacidad de acción unitaria en aquél.

4. Los equipos profesionales, tanto técnicos como de gestión, deben contar con habilidades de mediación y comunicación, y deben estar socialmente comprometidos. Este compromiso social implica una actitud tal que, sin renunciar a un desarrollo de unas actuaciones profesionales de la máxima calidad, por otra parte adecuadamente remuneradas, se identifiquen con la búsqueda de la mejora de la calidad de vida de una población en situación o en riesgo de vulnerabilidad o precariedad.

5. Se han de establecer criterios técnicos, de procedimiento, de gestión y de toma de decisiones por acuerdo entre técnicos, administración y población.

6. Se requiere determinar un marco normativo y de calidad de la rehabilitación, homogéneo en su alcance y objetivos.

7. Se necesita concretar un marco financiero viable en cuanto a las aportaciones públicas y privadas.

8. Es preciso elaborar una propuesta aceptable, global y unitaria que considere todos los aspectos técnicos, de gestión, de participación y de financiación. Se entiende que una propuesta es aceptable cuando integra los requisitos técnicos de adecuación a la normativa vigente con los deseos y necesidades expresados formalmente por la población a través de los cauces de participación ciudadana que se hubieran establecido.

9. Esta propuesta aceptable se debe difundir hasta ser formalmente aceptada por el máximo número de afectados.

La capacidad de los vecinos para comprender, decidir y poner en marcha las medidas necesarias para rehabilitar sus edificios es determinante para el éxito de la operación, hasta el punto de que gestión e intervención social prácticamente se identifican en muchos aspectos, y forman un todo indisoluble. Se han de crear las estructuras sociales y organizativas necesarias, con el nivel de formalidad y/o institucionalidad adecuado a aquellas capacidades.

Dado que, en general, las obras previstas no se perciben fácilmente como necesarias, parte de los vecinos plantearán dificultades para sufragar el coste que suponen las actuaciones. Ello conllevará un cierto nivel de escepticismo respecto a las posibilidades de la rehabilitación, y, en consecuencia, para que ésta se lleve a cabo. Se han de poner en marcha intensas campañas de sensibilización y, en su caso, incentivos económicos especiales.

Existirán, sin embargo, diferencias notables entre los diferentes conjuntos en relación con estas capacidades, por lo que se han de diseñar varias alternativas o modelos de gestión. Dentro de un marco general común, su operativa práctica difiere en función del mayor o menor protagonismo de la Administración y de las comunidades de propietarios.

Los tres modelos básicos son los siguientes:

- Gestión pública subvencionada. La Administración actúa como impulsora de la rehabilitación en cooperación con los propietarios. La Administración, a través de entidades gestoras de la rehabilitación y/o con la constitución de oficinas técnicas de rehabilitación, aportará la iniciativa y liderará el proceso. Es adecuada en conjuntos con importante patología y/o con población precaria o vulnerable. 



Figura 4. Imágenes de los edificios piloto antes y tras la rehabilitación en Zaragoza (fotografías tomadas por el autor). 
- Gestión privada subvencionada. La Administración no toma la iniciativa del proceso. Son los propietarios quienes la asumirán. La Administración tendrá las funciones de asesoría y de vigilancia del cumplimiento de los objetivos. Los propietarios se organizan con la creación de entes de gestión privados, mancomunidades de propietarios, etc. Es adecuada en conjuntos con patologías medias y con población con capacidad económica y organizativa. Su escala y desarrollo permiten introducir mejoras (aparcamientos, zonas ajardinadas, instalaciones colectivas).

- Gestión privada no subvencionada o con subvención limitada. La Administración ejerce su control a través de la normativa urbanística. Los propietarios constituyen Entes de Gestión Privados totalmente autónomos de la administración. Es adecuada en Conjuntos en que se han generado plusvalías importantes respecto de su situación original, con alto nivel constructivo y con población con importantes recursos. Su escala y desarrollo también permiten introducir mejoras.

La nueva Ley y el Plan Estatal 2013-2016 contemplan y formalizan parcial, pero suficientemente, las conclusiones anteriores de forma operativa, y pueden constituir una oportunidad importante para la activación del sector y para la creación de empleo. Las Asociaciones Administrativas contempladas en la Ley son análogas y pueden entenderse como la generalización de la figura de la Entidad Gestora creada para el desarrollo de las actuaciones de Caño Roto; y abren una vía de cooperación público-privada entre las administraciones y los beneficiarios organizados colectivamente.

Se habrá de estar atento al desarrollo práctico de esta Ley (30).

\section{REFERENCIAS}

(1) Alfaya Arias, V. (2014). Rehabilitación en España: una visión empresarial. ¿Puede la rehabilitación convertirse en una oportunidad para nuestra economía? En Menéndez, A. (Coord.), Por la rehabilitación, la regeneración y la renovación urbanas, Número monográfico de Ciudad y Territorio. Estudios territoriales, 2014(179): 99-107.

(2) Belmessous, F. (2012, 29-31 de octubre). La politique de la ville en francia: una visión particular de la cohesión social. Seminario «Regeneración Urbana Integrada: cohesión social, responsabilidad ambiental e integración urbana». Madrid: Universidad Politécnica de Madrid.

(3) Justo, A., Velázquez Soriano, I. (1991). Anotaciones sobre la política de vivienda en Europa y en España. Documentación social, 85: 19-32.

(4) Ruiz Palomeque, L. G. (2012, 29-31 de octubre). Integración Urbana: Conjuntos Urbanos de Zaragoza. Método de Planificación Técnica y Gestión para la Rehabilitación y la Regeneración Urbana. Seminario «Regeneración Urbana Integrada: cohesión social, responsabilidad ambiental e integración urbana». Madrid: Universidad Politécnica de Madrid.

(5) Ruiz Palomeque, L.G. (2013). Rehabilitación Integral del Poblado Dirigido de Caño Roto (Madrid). Un Modelo de Intervención en Grandes Conjuntos Urbanos. En Premios calidad Arquitectura y Vivienda 99+98 (p. 27). Madrid: Dirección General de Arquitectura y Vivienda de la Comunidad Autónoma de Madrid.

(6) Ruiz Palomeque, L.G., Rubio del Val, J. (2006). Nuevas propuestas de rehabilitación urbana en Zaragoza. Estudio de Conjuntos Urbanos de Interés, p. 290, Zaragoza: Sociedad Municipal de Rehabilitación Urbana de Zaragoza.

(7) López-Mesa, B., Palomero Cámara, J.I., Ortega Zapata, A., Amo Sancho, A.d. (2013). La rehabilitación y la mejora de la eficiencia energética de la vivienda social a examen. En Tejedor Bielsa, J. (Ed.), Rehabilitación y regeneración urbana en España. Situación actual y perspectivas. Monografías de la Revista aragonesa de Administración Pública, XV: $283-319$.

(8) INE. (2012). Censo de Población y Vivienda 2011. Madrid: Instituto Nacional de Estadística.

(9) Madrid. (2011). Fichas de ámbitos vulnerables. Banco de indicadores de la vulnerabilidad del suelo urbano de Madrid. Área de Gobierno de Urbanismo, Vivienda e Infraestructuras del Ayuntamiento de Madrid.

(10) Hernández Aja, A., Vázquez Espí, M., García Madruga, C., Matesanz Parellada, Á., Moreno García, E., Alguacil Gómez, J., Camacho Gutierrez, J. (2009-2011). Análisis Urbanístico de Barrios Vulnerables. Madrid: Universidad Politécnica de Madrid. http://habitat.aq.upm.es/bbvv/.

(11) Madrid (2011). Programa Municipal de Renovación Ambiental. Polígonos de Bloque Abierto. Área de Gobierno de Urbanismo, Vivienda e Infraestructuras. Departamento de Gestión Urbana y Estrategia Ambiental del Ayuntamiento de Madrid.

(12) Banco Mundial. (2014). Importaciones de energía, valor neto (\% del uso de energía). Banco Mundial. http://datos.bancomundial.org/indicador/EG.IMP.CONS.ZS.

(13) Banco de España. (2014). Estadística de Aduanas 18.2. Importaciones por productos. Banco de España. http://www. bde.es/webbde/es/estadis/infoest/bolest18.html.

(14) IDAE. (2014). Estudio sobre consumo energético del sector residencial en España. Instituto para la Diversificación y Ahorro de Energía. http://www.idae.es/index.php/id.171/mod.noticias/mem.detalle.

(15) Comisión Europea. (2013). Estrategia Europa 2020. http://ec.europa.eu/europe2020/index_es.htm.

(16) Rubio del Val, J. (2011). Rehabilitación Urbana en España (1989-2010). Barreras actuales y sugerencias para su eliminación. Informes de la Construcción, 63(Extra): 5-20, doi: http://dx.doi.org/10.3989/ic.11.060.

(17) Ruiz Palomeque, L.G. (2014). La gestión de la rehabilitación: barreras y escalas. Curso CM2-La rehabilitación energética de edificios. Instituto de Arquitectura. Fundación COAM.

(18) ETSAM, MFOM. (2010). Observatorio de la Vulnerabilidad En España. Catálogo de Barrios Vulnerables. Convenio realizado entre el Seminario de Planeamiento y Ordenación del territorio de la Sección de Urbanismo del Instituto Juan Herrera de la Escuela Técnica Superior de Arquitectura de Madrid (ETSAM) y el Ministerio de Fomento (MFOM). http://www.dgfc.sgpg.meh.es/sitios/dgfc/es-ES/ipr/fcpo713/c/ac/aa/Documents/AGUST\%C3\%8DN\%20 HERN\%C3\%81NDEZ.PDF. 
(19) Instituto Cerdá. (2010). Informe BREV. Beneficios de la rehabilitación de viviendas en la generación de actividad económica, creación de empleo y el ahorro de energía en el País Vasco. Departamento de Vivienda, Obras Públicas y Transportes del Gobierno Vasco.

(20) Comisión Europea. (2011). Política de Cohesión 2014-2020. http://ec.europa.eu/regional_policy/sources/docgener/informat/2014/financial_instruments_es.pdf.

(21) DGFC. (2014) Fondos Comunitarios: periodo 2014-2020. Dirección General de Fondos Comunitarios, Ministerio de Hacienda y Administraciones Públicas. http://www.dgfc.sgpg.meh.es/sitios/DGFC/es-ES/ipr/fcp1420/Paginas/inicio. aspx.

(22) MF. (2013). Real Decreto 233/2013, de 5 de abril, Plan Estatal de Fomento del Alquiler de viviendas, la Rehabilitación edificatoria, y la Regeneración y Renovación Urbanas, 2013-2016, Boletín Oficial del Estado n ${ }^{\circ} 68$.

(23) Rubio del Val, J. (2014). Nuevas iniciativas locales sobre regeneración urbana en el marco de la Ley 8/2013: una nueva lectura de la ciudad construida. Hacia nuevos modelos de gestión. Ciudad y Territorio, 179:109-125.

(24) Ruiz Palomeque, L. G. (2011). Propuesta para la puesta en marcha de programas de desarrollo sostenible en grandes conjuntos urbanos, p. 10, Asesoramiento técnico y coordinación para la puesta en marcha del programa de revitalización del barrio Picarral-Balsas de Ebro Viejo de Zaragoza. Área de rehabilitación y proyectos de innovación residencial de la Sociedad Municipal Zaragoza Vivienda S.L.U.

(25) Construmática. Cubierta a la Catalana http://www.construmatica.com/construpedia/Tipolog\%C3\%ADas_de_Cubiertas_Planas\#Cubierta_Ventilada_a_la_ Catalana.

(26) Ruiz Palomeque, L.G. (2009, 17-19, junio). Método sistemático para la rehabilitación de grandes conjuntos urbanos (p. 20). III Jornadas sobre investigación en Arquitectura y Urbanismo. Madrid: Universidad Politécnica de Madrid.

(27) Rubio del Val, J. (2013). La rehabilitación integral de algunos Conjuntos Urbanos en Zaragoza. Una oportunidad para el reciclado sostenible de la ciudad. En Tejedor Bielsa, J. (Ed.), Rehabilitación y regeneración urbana en España. Situación actual y perspectivas. Monografías de la Revista aragonesa de Administración Pública, XV: 237-282.

(28) Entrevista a Juan Rubio del Val. (2012). Revitalización Urbana de Zaragoza, p. 9, Habitat Futura. http://www.donostia.org/home.nsf/o/AACBA7AD763E7406C1257A320033F8AC/\$file/Habitat_Futura_Zaragoza_ Vivienda.pdf.

(29) Rodriguez Alonso, R. (2009). La política de vivienda en España en el contexto europeo. Dudas y retos. Madrid: Universidad Politécnica de Madrid. http://habitat.aq.upm.es/boletin/n47/arrod_2.html.

(30) Parkinson, M. (2014). Regeneración urbana integrada en 2014: nada nuevo bajo el sol. ¿Qué pasa con España? En Menéndez, A. (Coord.), Por la rehabilitación, la regeneración y la renovación urbanas, Número monográfico de Ciudad y Territorio. Estudios territoriales, 2014(179): 11-27. 